\title{
Discursos telejornalísticos: considerações sobre os termos ambientais na TV - estudo de caso no sul da Bahia. ${ }^{1}$
}

\author{
${ }^{2}$ Betânia Maria Vilas Bôas Barreto \\ ${ }^{3}$ Rodrigo Bomfim Oliveira
}

\section{Resumo}

O presente trabalho pretende averiguar como a televisão regional, na cidade de Itabuna, no sul da Bahia, aborda temas relativos às questões ambientais. É feito um estudo de caso com o programa jornalístico temático "Encontro Com", averiguando como os termos técnico-ambientais se encontram no discurso televisivo. Os procedimentos metodológicos voltar-se-ão para uma análise quantitativa dos termos e do método de análise de materiais audiovisuais. Serão discutidos aspectos qualitativos a partir do discurso das matérias e dos entrevistados para identificar o nível de entendimento passado e a intenção educativa voltada para o conhecimento do público sobre o meio ambiente.

Palavras-chave: Televisão regional - Jornalismo - Meio ambiente Educação

\section{Introdução}

Os meios de comunicação de massa, os chamados mass media, assumiram uma posição de destaque na sociedade contemporânea, não só pela capacidade de transmissão de informações, mas, principalmente, por servirem de instrumentos formadores de opinião. Bordenave (2001) explica que

"[...] os media fazem um papel de mediação entre a realidade e as pessoas. O que eles nos entregam não é a realidade, mas a sua construção da realidade. Isto é, da enorme quantidade de fatos e

\footnotetext{
${ }^{1}$ Trabalho inicial de pesquisa para o mestrado em Desenvolvimento Regional e Meio Ambiente do Prodema/UESC, sob a coordenação do Prof. Dr. Paulo dos Santos Terra. ${ }^{2}$ Jornalista, mestranda em Meio Ambiente e Desenvolvimento Regional e professora do Curso de Comunicação da UESC - Universdade Estadual de Santa Cruz, orientador: Prof. Dr. Manoel José Sene Dutra.

${ }^{3}$ Jornalista, publicitário e professor do Curso de Comunicação da UESC - Universidade Estadual de Santa Cruz. E-mail: rodrigo.surfer@uol.com.br
}

Comun. Inf., v. 7, n. 1, p.80-93, jan./jun. 2004 
situações que a realidade contém, os meios selecionam só alguns, os decodificam à sua maneira, os combinam entre si, os estruturam $\mathrm{e}$ recodificam formando mensagens e programas e os difundem, carregados, agora, da ideologia, dos estilos e das intenções que os meios lhes atribuem".

Ao se buscar estabelecer a relação existente entre meio ambiente $\mathrm{e}$ comunicação, percebe-se a necessidade de se ampliar o questionamento quanto à abrangência do conteúdo passado pelos meios massivos com relação aos temas ligados às questões ambientais. Essa abrangência leva à exigência de se criar mecanismos comunicacionais que possibilitem a conscientização quanto à realidade ambiental e de uma inter-relação entre meio ambiente e comunicação.

Ramos (1995) afirma que a Comunicação Social se insere nesse contexto da CiênciaAmbiental, "uma vez que os modelos tradicionais de análise compartimentalizada em áreas distintas do conhecimento se mostram insuficientes para a abordagem dos problemas complexos que envolvem o meio ambiente". Nessa perspectiva, a temática ambiental é essencialmente interdisciplinar e passa pelo âmbito comunicacional, para o conhecimento dos indivíduos. Ele aprofunda ainda mais a questão quando fala do paradoxo que existe na utilização dos mass media como veículos de transmissão de mensagens ambientais, já que

"[...] ao mesmo tempo em que desempenha o papel de ligação nos esforços na constituição de uma base de entendimento comum diante das diferentes leituras sobre o ambiente, a comunicação de massa é responsável tanto pela omissão quanto pela difusão indiscriminada de mensagens ambientais" (Ramos, 1995).

Para a Agenda 21 brasileira (2000), o papel dos meios de comunicação é o de ser responsável por "promover a conscientização pública sobre os temas da biodiversidade brasileira, da gestão dos recursos naturais e do desenvolvimento sustentável". Isso implica dizer que é necessário ser criada uma política de comunicação ambiental capaz de disseminar informações e conceitos, e de utilizar os veículos de comunicação - Rádio, TV, Impressos e Internet -, que passam a ter importante papel nas discussões ambientais e na formação de uma consciência ecológica.

Comun. Inf., v. 7, n. 1, p.80-93, jan./jun. 2004 


\section{2}

Dentre os principais meios comunicativos, a televisão evidenciouse por conseguir atingir, com o público, uma empatia e um alcance que a transformaram no mais popular veículo de comunicação do Brasil, valendo-se da junção dos dois principais sentidos humanos, o auditivo e o visual - por meio das imagens compartilhadas com o som.

Para Bosi (1989), "a TV é instrumento de informação rápida e certeira, uma forma extraordinária de educação plural e de socialização (no sentido universal do termo)". Por outro lado, a TV também é usada para direcionar contextos e opiniões, como os outros meios, demonstrando que "exerce um terrível poder de manipulação, que dispersa a atenção, embota a sensibilidade e aliena as consciências à forma de bombardear o receptor com imagens e sons em motocontínuo". Sob esse aspecto, o uso da televisão no âmbito das questões ambientais toma dimensões maiores, o que urge uma análise mais profunda do meio e de suas particularidades.

Daí a necessidade de se compreender o real potencial e a importância da TV como canal condutor dessas questões, sua influência e utilização como instrumento a serviço da conscientização ambiental, por meio da educação. Entende-se aí não somente a educação formal, passada pela escola, mas também o conjunto de informações recebido em sociedade, criando um referencial do mundo externo que interage com o conhecimento pessoal direto, assimilado pelo indivíduo mediante sua formação cultural, convivência social e experiência própria, levando à consolidação de opiniões sobre o mundo, a sociedade e o meio ambiente (Ramos, 1995).

Esta pesquisa pretende utilizar o meio televisivo como elemento que viabiliza a investigação dos processos comunicacionais na construção educativo-ambiental dos sujeitos, uma vez que a TV, ao estar inserida na escola, na família e nos processos educacionais, tornouse, nos dias atuais, um importante agente de formação (Baccega, 2000). Dessa forma, o ato de comunicar por meio da televisão também se torna um ato de educar, já que o alcance desse meio entre os indivíduos e a absorção das mensagens midiáticas, o coloca como potencial educador massivo, que precisa ser analisado como tal, na tentativa de investigar o conteúdo transmitido e sua forma, não apenas em seus diversos níveis (produção, circulação e recepção), mas também nos seus conteúdos (Napolitano, 2001). Segundo Machado, "sejam quais

Comun. Inf., v. 7, n. 1, p.80-93, jan./jun. 2004 
forem as nossas concepções com relação à televisão, a discussão sobre qualidade é quase sempre imprescindível. Fugir a essa discussão seria uma enorme irresponsabilidade". É sob esse ponto de vista que é realizada a construção desta pesquisa.

\section{O contexto da TV}

No sul da Bahia, os municípios de Ilhéus e Itabuna se destacam como referência regional, em suas dimensões econômica, social e cultural, sendo as duas principais cidades da região, onde vivem aproximadamente 410 mil pessoas. Segundo o IBGE (2000), $23 \%$ da população urbana e $60 \%$ da população rural da região é analfabeta. Nesse aspecto, os meios de comunicação de massa, principalmente a televisão, adquirem uma força ainda maior, pois se constituem fontes transmissoras de mensagens e formadoras de opinião que, não raro, são as únicas disponíveis para esse público.

Essa realidade é dimensionada a partir da localização dos centros comunicativos regionais. Em Itabuna ficam as sedes de duas das três emissoras de televisão existentes na região-TV Santa Cruze TV Cabrália -, que dispõem de programas televisivos produzidos por equipes locais, 0 que dá idéia da relevância da cidade no âmbito comunicacional.

Dentre as três emissoras de televisão, a TV Santa Cruz consegue atingir o maior índice de audiência na região, chegando a picos de até $73 \%$ (IBOPE, 2002) de televisores ligados na emissora. A sua cobertura atinge 58 municípios da região sul e extremo sul, alcançando uma audiência de aproximadamente 2 milhões de pessoas (Barreto e Albuquerque). A escolha da emissora deve-se ao fato de ser a que tem a maior abrangência geográfica em número de telespectadores em relação às outras duas televisões e por ter, em sua grade de programação local, um programa que é objeto da presente pesquisa: 0 telejornalístico "Encontro Com", produzido localmente e que trata de temas regionais relacionados a aspectos sociais, políticos, econômicos, comportamentais e culturais da região sul baiana.

O questionamento que se pretende aprofundar é o de saber como, nesse contexto da televisão regional, o aspecto relacionado ao meio ambiente é tratado televisualmente. Existe espaço para programas que tenham a intenção de educar efetivamente os indivíduos sobre as questões ambientais na região? Como o tema meio ambiente é Comun. Inf., v. 7, n. 1, p.80-93, jan./jun. 2004 


\section{4}

trabalhado audiovisualmente? Com isso espera-se abrir uma discussão sobre o assunto e trazer contribuições para o entendimento da complexidade entre a comunicação e a educação ambiental regional. Para Baccega (2000), é na complexidade do encontro da comunicação com a educação que "os sentidos se ressignificam e a capacidade de pensar criticamente a realidade, de conseguir selecionar informação (...) e de inter-relacionar conhecimentos, torna-se indispensável". Por ser um estudo introdutório, optou-se por uma centralização, em termos metodológicos, da análise televisiva.

\section{Metodologia}

A análise realizada neste artigo identifica como o programa televisivo "Encontro Com" passa a mensagem ambiental para o público local. O ponto central da pesquisa foi a definição de termos técnico-ambientais utilizados pelo programa e de que maneira eles foram expostos ao público.

A busca pelo método mais adequado de análise do conteúdo do programa baseou-se na complementaridade do próprio meio audiovisual como "amálgama complexo de sentidos, imagens técnicas, composição de cenas, seqüência de cenas e muito mais. Ė, portanto, indispensável levar essa complexidade em consideração, quando se empreende uma análise de seu conteúdo e estrutura" (Bauer e Gaskell, 2002). Os autores apontam que "o processo de análise de materiais audiovisuais envolve transladar" o material, fazer o levantamento amostral e escolher o foco de interesse de pesquisa.

Para o presente trabalho foi escolhido o levantamento dos termos ecológicos das edições dos três programas selecionados e como eles foram abordados ou não no contexto do discurso televisivo. Sabe-se, segundo esse procedimento, que o processo envolve escolhas, mas, no universo de número de programas e períodos de exibição, poucas edições foram encontradas sobre o tema, o que já dá um indício de pesquisa a ser verificado.

No encaminhamento da metodologia passou-se à transcrição dos programas para a averiguação da quantidade de termos técnicos e ambientais para serem analisados e se eles foram explicados ou não no contexto do programa. "A televisão é um meio audiovisual e deverá existir algum modo de descrever o visual, bem como a dimensão verbal" (Bauer e Gaskell, 2002). Nesse sentido, realizar um aprofundamento Comun. Inf., v. 7, n. 1, p.80-93, jan./jun. 2004 
maior da questão do discurso televisivo associado à imagem passada, no escopo do estudo introdutório em questão, não representou o objetivo do trabalho, visto que não foi realizada a interpretação geral de todos os aspectos audiovisuais (imagens, montagem, ilustrações), optando-se pelo recorte do discurso televisivo que, por si só, já dá uma referência de análise para a verificação do sentido passado para os telespectadores. E, no caso pesquisado, em se tratando de um telejornal temático, aborda um discurso que, segundo Machado, "se constrói da mesma maneira, se endereça de forma semelhante ao telespectador, fala sempre no mesmo tom de voz e utiliza o mesmo repertório de imagens sob qualquer regime político, sob qualquer modelo de tutela institucional (privado ou público), sob qualquer patamar de progresso cultural e econômico" (2001).

Dessa forma, a perspectiva qualitativa, em sua etapa descritiva, pretende dar suporte para que se descubram e se observem fenômenos televisivos, "procurando descrevê-los, classificá-los e interpretá-los", como diz Rudio (2002). Esse procedimento será básico para uma análise crítica da programação, avaliando-a sob outros enfoques, como espetáculo da realidade, texto estruturado e como exercício de expressão.

\subsection{Um "Encontro Com" o meio ambiente}

O elemento escolhido para o estudo - o programa telejornalístico "Encontro Com" - é exibido há cerca de três anos pela TV Santa Cruz (Rede Bahia de Televisão), afiliada da Rede Globo de Televisão e produzido localmente em Itabuna. O programa vai ao ar aos sábados, às $14 \mathrm{~h}$, e tem uma hora de duração. É um programa segmentado, que aborda um tema específico em cada edição, com várias reportagens sobre um mesmo assunto da atualidade regional e nacional. Dentre os temas abordados desde o início do programa, os ligados às questões ambientais fizeram parte da grade de programação apenas quatro vezes. Vale destacar que o programa é um dos poucos produzidos localmente que têm esse formato e características.

O programa, geralmente, é dividido em três partes, chamadas de blocos, com entrevistas em estúdio e várias matérias, sendo em média uma para cada segmento. Cada bloco tem a duração de vinte minutos, aproximadamente. O programa conta com um(a) apresentador(a) em estúdio, que anuncia a exibição das matérias e a apresentação de convidados que serão entrevistados ao longo do programa, para Comun. Inf., v. 7, n. 1, p.80-93, jan./jun. 2004 


\section{6}

trazerem maiores detalhes sobre o tema em questão. Geralmente, os entrevistados são especialistas ou trabalham diretamente com o assunto tema. $\mathrm{O}$ (a) apresentador(a) abre o programa anunciando o tema que será abordado, dá algumas informações sobre as reportagens que serão exibidas e, em seguida, apresenta o(s) convidado(s) da semana. Ele(a) começa conversando com os entrevistados sobre as noções gerais do tema e, a partir daí, anuncia a primeira matéria. Geralmente, depois dessa primeira matéria retorna-se ao estúdio para algumas considerações do entrevistado sobre o que foi mostrado. E assim transcorre o programa até o seu final, mesclando reportagens e debate do tema, com dois intervalos comerciais, e sempre retornando com a participação do(a) apresentador(a) e do(s) convidado(s) iniciando e concluindo cada bloco.

Foram analisadas três edições do programa, cujos temas foram: Reservas Particulares do Patrimônio Natural (RPPN), exibido em 27/ 07/2002; Manguezais, apresentado em 13/04/2002 e Qualidade da Água, em 07/07/2001. Foi feita uma observação, por meio da transcrição dos textos televisivos, e verificada a quantidade de termos ecológicos utilizada e como eles eram abordados no programa: se eram explicados, interpretados e decodificados nas abordagens. Não houve a ampliação da pesquisa para outros critérios da análise de discurso, visto que o objetivo era saber se os termos são definidos e se atingem uma explicação suficiente para o entendimento do público.

O programa não tem um caráter eminentemente científico-ambiental, não sendo um formato que aborde apenas temas ligados às questões ambientais. A proposta do programa é passar informações explicativas sobre os assuntos abordados, aprofundando o assunto com várias matérias. Aidéia transmitida é a de prestar esclarecimentos educativos, utilizando um texto que deixa transparecer essa intenção, como: "Vamos conhecer mais um pouco", "vamos saber o que é", "tudo isso para entendermos o que é", dentre outros.

Um dado importante é que em três anos de existência, apenas quatro edições trataram diretamente das questões ambientais. Só com esse dado verifica-se que, sendo um programa semanal, o número de edições sobre o assunto foi muito pequena, dando uma idéia de como o assunto é pouco explorado nesse contexto televisivo.

\section{A análise dos programas}

Os programas pesquisados trazem, de uma forma geral, conceitos

Comun. Inf., v. 7, n. 1, p.80-93, jan./jun. 2004 
e termos ambientais e ecológicos, expostos no discurso das matérias e nas entrevistas, e que, em alguns casos, não são explicados para os telespectadores. Foram catalogados 89 termos de uso técnico e ambiental nos três programas. Desse universo, $86,51 \%$ não foram explicados ou definidos e no restante, que corresponde a $13,49 \%$ do total, as colocações foram mencionadas. O critério de seleção dos termos baseou-se no grau de dificuldade de compreensão dos temas para o público em geral e na sua ligação com a área ambiental. Nessa referência inicial, pode-se notar a diferença existente entre o número de termos decodificáveis pelo público $(86,51 \%)$ e os que não tiveram maior aprofundamento no conteúdo das matérias e das entrevistas $(13,49 \%)$, podendo-se observar que a maioria dos termos nãofoi de fácil verificação pela audiência por meio do discurso televisivo.

Para Nelson (1994), "o principal desafio enfrentado pelos jornalistas que cobrem meio ambiente provavelmente é traduzir o palavreado científico em linguagem clara e concisa". O que se percebeu nos programas analisados foi que, em muitos casos, não só há falta de explicação, mas também de informações superficiais. $\mathrm{O}$ autor continua nesse raciocínio e alerta que

"[...] raramente um repórter escreve, intencionalmente, uma matéria que os leitores não podem entender. Mas muitos incluem termos que têm exatamente este efeito. O jornalista deve ter consciência de que algumas reportagens sobre meio ambiente são muito importantes para a vida das pessoas e justificam o esforço de traduzir o jargão ambientalista".

Nessa perspectiva, é necessário, para o bom entendimento do público, um aprofundamento maior sobre os temas propostos e um cuidado especial com a facilidade de decodificação das informações, principalmente as que são técnicas.

\subsection{As edições pesquisadas}

O primeiro programa foi dividido em três blocos, com uma matéria no primeiro bloco, duas no segundo e uma última no terceiro bloco. Ele tratou das Reservas Particulares do Patrimônio Natural (RPPNs). Foram utilizados 35 termos ambientais, o que corresponde a $39,32 \%$ dos termos pesquisados no total dos três programas. Desses $34,28 \%$ foram explicados aos telespectadores e $65,71 \%$ não foram. Termos como "cobertura vegetal", "unidades de conservação" e "reserva Comun. Inf., v. 7, n. 1, p.80-93, jan./jun. 2004 
biológica" foram citados, mas não esmiuçados. Por essa observação prévia, quase o dobro dos termos utilizados foi passado sem uma definição ou conceituação para o receptor. E são termos comumente utilizados na área ambiental, mas sem a mesma freqüência de uso em outras áreas do conhecimento.

O segundo programa analisado, que tratou dos manguezais de região sul baiana, foi composto também por três blocos, sendo duas matérias no primeiro bloco, uma no segundo e uma última no terceiro bloco. Nesse programa compareceram dois entrevistados ao estúdio, fazendo comentários sobre as matérias exibidas. Foram registrados nessa edição 28 termos técnico-ambientais, correspondendo a $31,46 \%$ do total. Destes, $83,14 \%$ não foram definidos e apenas $16,85 \%$ foram explicados. Nesse caso, como nos outros, o equívoco ocorre não somente no texto dos jornalistas, mas também no discurso dos especialistas que prestaram declaração ao programa, como no caso da definição dos tipos de mangue existentes no sul da Bahia. Um especialista entrevistado afirmou serem três tipos, enquanto outro afirmou serem quatro tipos. Isso demonstra a contradição, também, entre as fontes de informação buscadas para embasar as assertivas. Nelson (1994) alerta para a maneira como o jornalista deve checar as fontes de informação para a matéria:

"[...] é preciso observar se a fonte se expressa com clareza. Muitas pessoas brilhantes têm dificuldade de se comunicar com leigos. Se um cientista famoso não consegue explicar um assunto claramente, o repórter deve procurar alguém menos famoso, mas que tenha facilidade para explicar o tema".

O terceiro programa apresenta um quadro mais explícito dessa diferença, pois, do total de $30,35 \%$ termos utilizados, $96,29 \%$ não foram explicados e apenas $3,70 \%$ foram esclarecidos ao público. Nesse caso, o tema do programa era a água, e se deixou de explicar termos diretamente ligados ao tema, como "bacias hidrográficas" e "recursos hídricos".

\section{Discussão}

Diante desses dados introdutórios, o que se pode questionar é o que condiciona a estruturação de um programa jornalístico que aborda temas voltados ao meio ambiente. Linhares e Morais apontam que

Comun. Inf., v. 7, n. 1, p.80-93, jan./jun. 2004 
"[...] o jornalismo, enquanto produção de informação, dissemina conceitos, visões e propõe caminhos de interpretação da realidade, ancorados numa linguagem compatível com o meio ao qual se destina. No entanto, está sujeito às condições disponíveis - desde materiais ou de infra-estrutura, passando pelas econômicas, até as de ordem ideológica, e impostas pelas rotinas de produção"( (2002, p.03).

Nessa perspectiva, pode-se verificar alguns fatores que dão indícios sobre números tão distintos. Ao que parece, não existe uma preocupação explícita, por parte dos profissionais de comunicação, de detalhar os termos ao público e sim em simplificar os conteúdos técnicos, para facilitar a compreensão. Linhares e Morais verificam, ainda, que esse fato deve-se ao "caráter especial dessa atividade [que] está, entre outras coisas, na responsabilidade e no grau de conhecimento do jornalista sobre $o$ assunto que está tratando e 'simplificando' para garantir ao público de massa a compreensão do tema". E isso, às vezes, não chega aos resultados esperados. O questionamento levantado sobre a abrangência da temática ambiental exige maior grau de conhecimento específico, sendo que os profissionais não se encontram preparados devidamente para uma abordagem mais complexa e profunda do assunto, deixando na superficialidade conceitos e definições que enriqueceriam o cabedal de conhecimento da comunidade que $o$ programa pretende atingir.

Um outro dado levantado mostra que em algumas sonoras, dentro das matérias, alguns entrevistados mencionaram termos técnicos que passaram despercebidos no restante do texto, mesmo que eles fizessem parte decisiva para o entendimento geral do contexto do assunto. Podese notar, dessa forma, que pela escassez do tempo para cada material, muitos termos são deixados sem maiores explicações ou aprofundamento. A linguagem, nesse caso, é pautada pela palavra oral, de maneira superficial e, em alguns casos, contraditória. "Pode parecer mais fácil enganar uma pessoa desinformada do que uma pessoa com alguma informação, porque a primeira não possui dados que possam orientar as suas decisões". Isso se constata pela brevidade e simplificação do discurso, que é uma característica do meio televisivo. "Mas cabe a possibilidade de enganar o informado, dando-lhe informações erradas. Ou simplesmente informações parciais, ou seja, ocultando dados essenciais" (Ferrés, 1998). Seguindo esse Comun. Inf., v. 7, n. 1, p.80-93, jan./jun. 2004 
pressuposto, outro aspecto abordado foi a participação dos entrevistados no programa. Em média, são de seis a oito sonoras por matéria, sendo que vários personagens participam mais de uma vez, em mais de uma matéria, na mesma edição do programa. O que se percebeu foi que declarações obtidas por vários deles eram colocadas, de acordo com o contexto da matéria, em mais de um material ou mais de uma vez no mesmo material. Isso pode demonstrar que as fontes de informação conseguidas são geralmente as mesmas, implicando na fundamentação argumentativa do discurso do programa, tendendo a passar uma visão apenas unilateral e restrita. A estruturação da produção e a pesquisa das fontes trazem novamente a impressão de centralização da visão contextual passada ao telespectador, é o que Ferrés (1998) lembra quando aponta a fragmentação da mensagem passada pelos programas que "comunicam a partir de um ponto de vista determinado e o que transmitem é, obrigatoriamente, uma realidade fragmentada e descontextualizada".

No primeiro programa, por exemplo, foram ao todo 31 sonoras e destas, cinco foram de um mesmo entrevistado, que entrou em três matérias diferentes. Nesse programa, 11 declarações vieram de especialistas na área, o mesmo acontecendo no segundo programa, que contabilizou 29 sonoras, sendo que 11delas também eram de especialistas. No terceiro foram 43 sonoras, sendo $12 \mathrm{com}$ especialistas. Ao todo, contabilizam-se 44 depoimentos apenas de pessoas que têm um conhecimento mais aprofundado sobre meio ambiente. Num universo de 103 declarações, 42,71\% são de especialistas, o que passa, de início, a idéia de um caráter mais científico do conteúdo do programa. Mas, por outro lado, deixa a cargo de pessoas que, muitas vezes, não se expressam com clareza. Nelson (1994) alerta para a questão de não deixar unicamente à fonte a missão de passar a informação, deve ser interpretada pelo jornalista.

\section{Conclusão}

Esta breve análise do discurso utilizado pelo programa em questão para se referir às questões ambientais mostra, de forma preliminar, a existência de pouco entendimento entre o conhecimento científico ambiental e as informações que são utilizadas pelo programa telejornalístico. Ao que parece, existe uma falta de aprofundamento

Comun. Inf., v. 7, n. 1, p.80-93, jan./jun. 2004 
dos temas e dos conceitos básicos de termos que são utilizados na área, muitas vezes, de maneira equivocada.

O que se conclui é que há despreparo para o trato do assunto pelos profissionais de comunicação, não bastando recorrer a especialistas da área que possam abordar mais convenientemente $o$ tema, já que a forma de estruturação e montagem do próprio discurso televisivo, por seu caráter superficial, omite ou redireciona posicionamentos e informações. Pode-se ter uma idéia de como os temas ambientais são pouco abordados pelos meios de comunicação de massa, em particular a televisão da região, quando se tem um quadro do programa pesquisado que, em três anos de existência, produziu apenas quatro programas sobre o assunto. Isso leva a uma reflexão sobre como o assunto tem pouca relevância para a empresa televisiva, visto que para ser selecionado passa por alguns critérios "determinados pela empresa de comunicação em sintonia com o conjunto de interesses do público, além de outras interferências, que concorrem entre si para definir o 'temário dos meios' - o conjunto de conteúdos informativos e noticiosos existentes em um meio" (Linhares e Morais apud Fontcuberta, 1993). Pela quantidade de edições, percebe-se que o tema meio ambiente é pouco explorado televisualmente.

Dessa forma, fica a evidência da necessidade de uma reflexão maior sobre a questão ambiental por parte dos profissionais e das empresas de comunicação, e demais profissionais da área na região sul da Bahia, para um embasamento mais adequado em termos de conteúdo educativo ambiental a ser passado aos telespectadores, para uma efetiva contribuição à conscientização ecológica, à educação ambiental e à cidadania.

O presente estudo não aprofunda mais a questão proposta porque, como foi dito anteriormente, é uma pesquisa introdutória, que faz parte da elaboração da dissertação de mestrado em Desenvolvimento Regional e Meio Ambiente, que está em sua fase inicial, e que será realizada sob a ótica da análise de discurso do meio televisivo em relação às questões educativo-ambientais. Cabem novas e mais aprofundadas reflexões sobre o tema, que é muito vasto, para uma contribuição mais eficiente para o entendimento do problema, o que será o resultado final a ser apresentado.

Comun. Inf., v. 7, n. 1, p.80-93, jan./jun. 2004 


\section{Abstract}

The present research intends to exam how the local television, held in in environmental issues. It is done a case study through a tiny look at a thematic journalism program "Encontro Com", by asking how the technical environmental terms are used in the television speech. The methodological procedures will support quantitative analyses of the TV terms found in the stories and through the method of audiovisual analyses. Qualitative aspects will be discussed based upon the stories' speech and by interviews in order to identify the level of understanding and the educative intention directed to the public's knowledge about the environment.

Key words: Local Television - Journalism - Environment - Education

\section{Referências}

BACCEGA, Maria Aparecida. Comunicação/Educação: aproximações In : A TV aos 50 - Criticando a TV Brasileira no seu Cinqüentenário. SP: Fundação Perseu Abramo, 2000. 201p.

BARRETO, Betânia. ALBUQUERQUE, Eliana. Mundo global X Mundo regional: a influência da televisão no pensar, sentir e fazer regional. Trabalho apresentado no 10 Congresso do Redecom - Salvador, BA, 2002. 13p.

BORDENAVE, Juan E. Diaz. Além dos meios e mensagens. RJ: Vozes, 2001.119p.

BOSI, Alfredo. In Linguagem Autoritária - Televisão e Persuasão. SP: Brasiliense, 1999.200p.

BAUER, Mortim W.; GASKELL, George (org.). Pesquisa quantitativa com texto, imagens e som. Trad. Guareschi, Pedrinho A Petrópolis, RJ: Vozes, 2002.

BUCCI, Eugênio (org). A TV aos 50 - Criticando a TV Brasileira no seu Cinquentenário. SP: Fundação Perseu Abramo, 2000. 201p.

FERRÉS, Joan. Televisão Subliminar. Trad. Ernani Rosa e Beatriz A. Neves. Porto Alegre: Artes Médicas, 1998. 160.

LINHARES, Maria Gorete de A.; MORAIS, Wilma Peregrino de. Diversidades de um discurso sobre o meio ambiente. In: Anais do XXV Congresso Brasileiro de Comunicação - Intercom - Salvador, 2002. NELSON, Peter. Dez dicas práticas para reportagem sobre meio ambiente. Centro de Jornalistas Estrangeiros/WWF, 1994.

MACHADO, Arlindo. A televisão levada a sério. 2 ed. SP: Editora Comun. Inf., v. 7, n. 1, p.80-93, jan./jun. 2004 
SENAC, 2001. P.104-126

MINISTÉRIO DO MEIO AMBIENTE. Agenda 21 Brasileira. Ações prioritárias. Brasília: MMA, 2000. 191p.

NAPOLITANO, Marcos. Como Usar a Televisão na Sala de Aula. SP: Contexto, 2001.136p.

RAMOS, Luiz Fernando A. Meio Ambiente e Meios de Comunicação.

SP: Annablume, 1995. 159p.

RUDIO, Franz Victor. Introdução ao Projeto de Pesquisa Científica.

Petrópolis: Vozes, 1986.144p.

CENSO IBGE 2000. In: http://www.sei.ba.gov.br - acessado em 16/05/2003

Comun. Inf., v. 7, n. 1, p.80-93, jan./jun. 2004 